\title{
Manejo do pastejo de cultivares de Brachiaria brizantha (Hochst) Stapf e de Panicum maximum Jacq
}

\author{
Valéria Pacheco Batista Euclides ${ }^{1}$, Denise Baptaglin Montagner ${ }^{2}$, Rodrigo Amorim Barbosa ${ }^{3}$, \\ Nayana Nazareth Nantes ${ }^{4}$ \\ http://dx.doi.org/10.1590/0034-737X201461000006
}

\begin{abstract}
RESUMO
A definição dos princípios adequados de manejo do pastejo capazes de possibilitar que as pastagens mantenhamse produtivas e persistentes tem sido uma preocupação constante dos pesquisadores brasileiros. No entanto, foi durante as duas últimas décadas que ocorreram grandes mudanças e um avanço significativo na compreensão dos processos determinantes da correta utilização das plantas forrageiras tropicais em pastagens. Este texto tem por objetivo apresentar e discutir os principais resultados obtidos sobre o manejo do pastejo de alguns cultivares de Panicum maximum e de Brachiaria brizantha, bem como a importância da utilização de metas de pasto como guia de campo para o monitoramento e controle do processo de pastejo para planejar e recomendar práticas de manejo eficientes.
\end{abstract}

Palavra-chave: Acúmulo de forragem, altura do dossel, desempenho animal, estrutura do dossel, valor nutritivo.

\section{ABSTRACT}

\section{Pasture and grazing management of Brachiaria brizantha (Hochst) Stapf and Panicum maximum Jacq}

Defining a proper grazing management that allows pasture to remain productive and persistent has been a constant concern of Brazilian researchers. However, it was in the last two decades that significant changes have taken place regarding the understanding of important processes determining the use of tropical forage plants in pastures. The objective of this article is to present and discuss the main results on grazing management of some Panicum maximum and Brachiaria brizantha cultivars, as well as the importance of using pasture goals to guide planning, controlling and recommending efficient grazing management practices.

Key words: animal performance, herbage accumulation, sward height, sward structure, nutritive value.

\footnotetext{
Recebido para publicação em 24/05/2014 e aprovado em 20/11/2014.

${ }^{1}$ Engenheira-Agrônoma, PhD. Embrapa Gado de Corte, Avenida Rádio Maia, 830, 79106-550, Campo Grande, Mato Grosso do Sul, Brasil. valeria.pacheco@embrapa.br (autora para correspondência)

2 Zootecnista, Doutora. Embrapa Gado de Corte, Avenida Rádio Maia, 830, 79106-550, Campo Grande, Mato Grosso do Sul, Brasil. denise.montagner@embrapa.br

3 Engenheiro-Agrônomo, Doutor. Embrapa Gado de Corte, Avenida Rádio Maia, 830, 79106-550, Campo Grande, Mato Grosso do Sul, Brasil. rodrigo.barbosa@embrapa.br

4 Zootecnista, Mestre. Departamento de Zootecnia, Universidade Federal de Mato Grosso do Sul, Avenida Filinto Müller, 79080-190, Campo Grande, Mato Grosso do Sul, Brasil. nayzootecnia@hotmail.com
} 


\section{INTRODUÇÃO}

Segundo estimativas de Dias-Filho (2011), cerca de 70 milhões de hectares de pastagens cultivadas existentes no território nacional encontram-se degradadas ou em algum grau de degradação. Merece ainda destaque o fato de os esforços que vêm sendo encetados por diferentes programas estarem concentrados na recuperação dessas áreas sem, contudo, contemplar sua manutenção por meio de manejo adequado. É na manutenção inadequada que reside grande parte dos problemas de degradação e de baixos níveis de produção, perpetuando as dificuldades para se aumentar a taxa de lotação dos pastos. Tal incremento poderia não só liberar áreas para a agricultura, mas também permitiria melhor uso da logística instalada.

Assim, manutenção de níveis de produção forrageira satisfatórios, compatíveis com o clima e com as condições físico-químicas do solo, de forma a manter o sistema sustentável ao longo do tempo constitui-se, hoje, em um dos grandes problemas da pecuária. As principais causas para que o complexo solo-planta entre em processo de degradação são: a falta de reposição de nutrientes no solo; o manejo do pastejo inadequado; e as práticas culturais inadequadas; podendo, ainda, serem agravadas pelo déficit hídrico, pragas e doenças. Dessa forma, a reversão do processo de degradação das pastagens faz deste o principal problema a ser abordado pela pesquisa em pastagens cultivadas. A expectativa é que a definição e a transferência dos princípios adequados de manejo capazes de possibilitar que as pastagens dos capins mais utilizados no sistema de produção mantenhamse produtivas e persistentes, aumentando a rentabilidade do agronegócio, tanto pela redução da degradação das pastagens como pelo aumento da produção animal, concorrendo, ainda, para a mitigação de impactos ambientais via manutenção da produtividade das pastagens.

\section{MANEJO DO PASTEJO}

Segundo Nascimento Jr. et al. (2003), o conhecimento relativo à morfogênese e ecofisiologia das plantas forrageiras e à ecologia do pastejo tem adquirido grande importância, assumindo papel de destaque e constituindo premissa básica para a idealização e recomendação de práticas de manejo sustentáveis, que permitam aumentar a produção e a produtividade dos sistemas de produção, respeitando os limites e as características específicas do ecossistema.

No final da década de 1990, esses conceitos começaram a ser incorporados nos protocolos experimentais para a avaliação de pastagens. As mudanças significativas e os avanços que ocorreram em relação à compreensão dos principais fatores e processos que determinam o uso adequado das gramíneas tropicais podem ser encontrados no trabalho de revisão elaborado por Da Silva e Nascimento Jr. (2007). Essas mudanças de paradigma tem gerado grande banco de dados que tem orientado as estratégias de utilização da pastagem.

\section{LOTAÇÃO INTERMITENTE}

Com base nos resultados dos trabalhos pioneiros com os culvivares de P. maximum Mombaça (Carnevalli et $a l, 2006)$ e Tanzânia (Barbosa et al., 2007) e com os cultivares B. brizantha Xaraés (Pedreira et al, 2007) e Marandu (Giacomini et al., 2009), submetidos à lotação rotacionada, foi possível demonstrar que o conceito de índice de área foliar crítico, condição na qual as interceptações do pasto de $95 \%$ da luz incidente, utilizado para o manejo de gramíneas de clima temperado, é válido e pode ser aplicado para as gramíneas tropicais. Esses autores observaram que o maior acúmulo de lâminas foliares foi obtido quando esses capins interceptavam $95 \%$ da luz e que a interrupção do período de rebrotação, além desse ponto, resultou em alterações indesejáveis na estrutura do dossel forrageiro, caracterizadas pelo acúmulo excessivo de colmo e material morto na massa de forragem no pré-pastejo. Portanto, o melhor momento para interromper o processo de crescimento é quando o dossel apresenta 95\% de interceptação de luz (IL), garantindo, dessa forma, a produção de forragem de alta qualidade.

Além disso, os autores observaram grande correlação entre a altura do dossel e sua IL, indicando que a altura do dossel poderia ser usada como alvo de manejo confiável para monitoramento da frequência e da intensidade de pastejo. Experimentos análogos foram conduzidos com outros cultivares de $P$. maximum e de $B$. brizantha, e as alturas de pasto em que se constatou a interceptação de $95 \%$ da luz incidente para alguns capins são apresentadas na Tabela 1.

Nesse contexto, Gimenes et al. (2011) avaliaram a produção animal em pastos de capim-marandu, submetidos ao pastejo rotacionado, com duas frequências de pastejo, que foram definidas de acordo com as alturas dos pastos, $25 \mathrm{~cm}$ (correspondente a 95\% IL) e $35 \mathrm{~cm}$ (correspondente a 100\% IL), e duas doses de fertilizante nitrogenado (50 e $200 \mathrm{~kg} / \mathrm{ha}$ de $\mathrm{N}$ por ano). Todas as estratégias de manejo foram associadas a uma condição de pós-pastejo de $15 \mathrm{~cm}$. A aplicação de $\mathrm{N}$ acelerou o crescimento das plantas, o que aumentou o número de ciclos de pastejo, sendo o maior número registrado para o tratamento $25 \mathrm{~cm} / 200 \mathrm{~kg}$ de $\mathrm{N}$ (9,3 ciclos) e o menor para o tratamento $35 \mathrm{~cm} / 50 \mathrm{~kg}$ de N (5,1 ciclos). Independentemente das doses de $\mathrm{N}$, pastos manejados com $25 \mathrm{~cm}$ de altura apresentaram maiores taxas de lotação e 
ganhos de peso por animal e por área em relação aos manejados a $35 \mathrm{~cm}$ (Tabela 2). O melhor desempenho dos animais nos pastos manejados a $25 \mathrm{~cm}$ foi resultado do melhor valor nutritivo da forragem consumida, caracterizada pela maior porcentagem de folhas $(83,1$ vs $77,3 \%)$ e pelas menores porcentagens de colmos $(9,3$ vs $11,9 \%)$ e de material morto (7,2 vs 11,2\%). Além disso, os autores observaram que as perdas por pastejo foram superiores nos pastos manejados com $35 \mathrm{~cm}(24,1 \%$ da massa de forragem pré-pastejo) do que aqueles com $25 \mathrm{~cm}$ (20,3\% da massa de forragem pré-pastejo). Dessa forma, baseado na produção animal ratificou-se que, independentemente da dose de nitrogênio utilizada, a rebrotação do capim-marandu deve ser interrompida quando a altura do dossel atingir $25 \mathrm{~cm}$.

A partir dessa informação, tornou-se necessário identificar o momento adequado para a retirada dos animais do pasto; ou seja, a determinação do resíduo pós-pastejo adequado. As amplitudes de altura para o resíduo pós-pastejo de alguns cultivares dos gêneros Panicum e Brachiaria, dentro dos quais o pasto pode ser manejado sem prejuízo para a planta forrageira e consequente degradação do pasto, encontram-se na Tabela 1.

É importante ressaltar que, geralmente, o aumento da intensidade de pastejo resulta em melhoria da eficiência de pastejo; entretanto, a produção por animal é reduzida. Isso reforça a importância de se avaliar a resposta do animal para a definição do resíduo pós-pastejo adequado para otimizar as produções por animal e por área.

Nesse contexto, a importância do ajuste da intensidade de pastejo como forma de regular o nível de desempenho almejado e, ou, gerar flexibilidade de manejo no sistema de produção foi demonstrada por Difante et al. (2010) e Euclides et al. (2012b), que avaliaram, respectivamente, pastos de capim-tanzânia e de capim- mombaça submetidos a estratégias de lotação rotacionadas definidas por metas de pré-pastejo de $95 \%$ de IL e dois resíduos pós- pastejo (Tabela 3). Difante et al. (2010) concluíram que para o pasto de capim-tanzânia a altura pós-pastejo poderia variar de 25 a $50 \mathrm{~cm}$, dependendo se o objetivo do manejo fosse a melhoria do ganho de peso por área (maior eficiência de pastejo) ou o ganho por animal (Tabela 3).

Já para o capim-mombaça, Euclides et al. (2012b) observaram que o número de animais extras (1,2 UA/ha) utilizados no pasto manejado com resíduo de $30 \mathrm{~cm}$ não foi suficiente para compensar o menor ganho de peso individual (290 g/animal por dia a menos), resultando em menor ganho de peso por área (Tabela 3). Assim, esses autores concluíram que o capim-mombaça submetido ao pastejo rotacionado deve ser manejado com a meta de resíduo de $50 \mathrm{~cm}$ de altura. As eficiências de colheita foram, em média, 78 e $62 \%$, respectivamente, para os pastos manejados com as metas de resíduo de 30 e $50 \mathrm{~cm}$, o que está de acordo com a proposição feita por Carvalho et al. (2004) de que o melhor uso do pasto se dá na faixa de 50 a $60 \%$ de eficiência de pastejo, quando ocorre otimização dos ganhos de peso por animal e por área.

Dadas às variações sazonais entre anos e as doses de nitrogênio aplicadas, houve variações substanciais nos intervalos de pastejo para atingir as alturas-meta préestabelecidas (Tabela 3).

O manejo baseado em dias fixos e pré-determinados de descanso, apesar de facilitar o planejamento do pastejo rotacionado, pode restringir a produção animal, pois não gera padrão uniforme de resposta fisiológica da planta, resultando em dosséis de estrutura variável. Nesse contexto, Euclides et al. (2012a) avaliaram a produção animal em pastos de capim-tanzânia submetidos a duas estratégias de desfolhação intermitente, com intervalos de pastejo fixo (IPF) e variável (IPV), este defi-

Tabela 1. Alturas pré e pós-pastejo recomendadas para manejo de cultivares Panicum maximum e de Brachiaria brizantha submetidos à lotação rotacionada

\begin{tabular}{|c|c|c|c|}
\hline \multirow[b]{2}{*}{ Gramíneas } & \multicolumn{2}{|c|}{ Altura do pasto $(\mathrm{cm})$} & \multirow[b]{2}{*}{ Referência } \\
\hline & Pré-pastejo & Pós-pastejo & \\
\hline \multicolumn{4}{|c|}{ Panicum maximum } \\
\hline Aruana & 30 & 15 & Zanini et al.,2012 \\
\hline Massai & 55 & 15 a 30 & Barbosa et al., 2010 \\
\hline Milênio & 90 & 30 a 50 & Barbosa et al., 2009 \\
\hline Mombaça & 90 & 30 a 50 & Carnevalli et al., 2006 \\
\hline Tanzânia & 70 & 25 a 50 & Barbosa et al., 2007 \\
\hline \multicolumn{4}{|c|}{ Brachiaria brizantha } \\
\hline Marandu & 25 & 15 & Giacomini et al., 2009 \\
\hline Xaraés & 30 & 15 & Pedreira et al., 2009 \\
\hline Mulato $^{1}$ & 30 & 20 & Silveira et al. (2013) \\
\hline
\end{tabular}

${ }^{1}$ Híbrido interespecífico de B. ruziziensis e B. brizantha. 
nido em razão da altura do pasto de $70 \mathrm{~cm}$ (correspondente a $95 \%$ de IL, Tabela 4). Ambas associadas a um resíduo pós-pastejo comum de $35 \mathrm{~cm}$ de altura. Esses autores observaram maior valor nutritivo e melhor estrutura do dossel para o pasto manejado com o IPV, consequentemente maior desempenho animal quando comparado àquele com IPF (Tabela 4). O número de animais extras (Figura 1) colocados no pasto com IPF não foi suficiente para compensar o menor ganho de peso individual, resultando em menor ganho de peso por área (Tabela 4). Assim, a diferença entre os ganhos de peso por animal e por área a favor da utilização do IPV justifica o monitoramento das alturas dos pastos, as reduções no intervalo entre pastejo e os ajustes da taxa de lotação
(Figura 1) necessários para a manutenção das metas de manejo, principalmente nos meses de maior crescimento da forrageira.

É importante ressaltar que na região Centro-Oeste o período seco é bem definido, de maio a setembro. No entanto, as condições climáticas ótimas para o crescimento dos capins mombaça e tanzânia só foram restabelecidas em meados de novembro (Figuras 1 e 2). Nessa região, os cultivares de $P$. maximum, Mombaça (Cunha et al., 2010) e Tanzânia (Barbosa et al., 2007; Difante et al., 2010) somente atingiram índice de área foliar ótimo após novembro. Assim, optou-se por iniciar o pastejo logo após as primeiras chuvas, quando os primeiros piquetes, de cada módulo, a serem pastejados,

Tabela 2. Números de ciclo de pastejo, taxa de lotação, ganhos de peso por animal e por área em pastos de capim-marandu submetidos à lotação rotacionada com duas alturas de pré-pastejo e duas doses de adubação nitrogenada

\begin{tabular}{lcccccc}
\hline & \multicolumn{2}{c}{ Altura do pasto $(\mathbf{c m})$} & & \multicolumn{2}{c}{ Adubação nitrogenada $(\mathbf{k g} / \mathbf{h a ~ d e ~ N )}$} \\
\cline { 2 - 3 } \cline { 6 - 6 } & $\mathbf{2 5}$ & 3,13 & $\mathbf{3 5}$ & & $\mathbf{5 0}$ & $\mathbf{2 0 0}$ \\
\hline Taxa de lotação (UA/ha) & 0,630 & 2,85 & & 2,55 & 3,45 \\
Ganho médio diário (kg/animal) & 886 & 0,515 & & 0,585 & 0,555 \\
Ganho por área (kg/ha) & & 673 & & 697 & 863 \\
\hline
\end{tabular}

Fonte: Adaptado de Gimenes et al. (2011).

Tabela 3. Taxa de lotação (TL) e ganhos de peso por animal e por área de pastos de capins tanzânia e mombaça, submetidos a duas intensidades de pastejo

\begin{tabular}{|c|c|c|c|c|c|c|}
\hline \multirow{2}{*}{ Período (dias) } & \multicolumn{2}{|c|}{ Altura do pasto $(\mathrm{cm})$} & \multirow{2}{*}{$\begin{array}{c}\text { TL } \\
\text { (UA/ha) }\end{array}$} & \multicolumn{2}{|c|}{ Ganho de peso $(\mathrm{kg})$} & \multirow{2}{*}{ Número de ciclos } \\
\hline & Pré & Pós & & Animal & área & \\
\hline \multicolumn{7}{|c|}{ 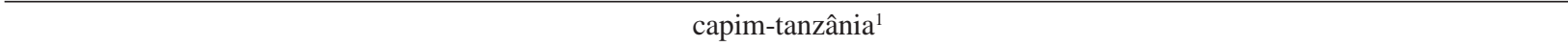 } \\
\hline \multirow[b]{2}{*}{156} & \multirow[b]{2}{*}{70} & 25 & 6,1 & 0,665 & 600 & 3,0 \\
\hline & & 50 & 4,9 & 0,800 & 560 & 5,0 \\
\hline \multicolumn{7}{|c|}{ capim-mombaça ${ }^{2}$} \\
\hline 164 & \multirow[t]{2}{*}{$90^{3}$} & 30 & 7,7 & 0,380 & 545 & 5,0 \\
\hline 177 & & 50 & 6,5 & 0,670 & 945 & 6,0 \\
\hline \multicolumn{7}{|c|}{ capim-mombaça ${ }^{2}$} \\
\hline \multirow{2}{*}{236} & \multirow{2}{*}{$90^{4}$} & 30 & 6,7 & 0,390 & 640 & 6,0 \\
\hline & & 50 & 5,1 & 0,655 & 1.070 & 7,3 \\
\hline
\end{tabular}

${ }^{1}$ Adubação: $500 \mathrm{~kg} \mathrm{ha}^{-1}$ de 0-20-20 e $150 \mathrm{~kg} \mathrm{~kg} \mathrm{ha}^{-1}$ de N (Difante et al., 2010).

${ }^{2}$ Adubação: $400 \mathrm{~kg} \mathrm{ha}^{-1}$ de 0-20-20 e $200 \mathrm{~kg} \mathrm{~kg} \mathrm{ha}^{-1}$ de N (Euclides et al., 2012b).

${ }^{3}$ Considerando apenas os pastos que atingiram a altura-meta de $90 \mathrm{~cm}$ (Euclides et al., 2012b)

${ }^{4}$ Durante o primeiro e o último ciclos de pastejo as alturas dos pastos ficaram abaixo da altura-meta de $90 \mathrm{~cm}$ (Euclides et al., $2012 \mathrm{~b}$ ).

Tabela 4. Taxa de lotação e ganhos de peso por animal e por área de pastos de capim-tanzânia em pastejo rotacionado com intervalos de pastejo fixo e variável (meta de $70 \mathrm{~cm}$ de altura)

\begin{tabular}{lcccc}
\hline \multirow{2}{*}{ Estratégia de manejo } & \multirow{2}{*}{ Período (Dias) } & TL (UA ha) & \multicolumn{2}{c}{ Ganho de peso (kg) } \\
\cline { 4 - 5 } & & & animal & Área \\
\hline Fixo & 216 & 5,4 & 0,660 & 860 \\
Variável $^{1}$ & 216 & 4,3 & 0,780 & 990 \\
Variável $^{2}$ & 159 & 5,1 & 0,830 & 890 \\
\hline
\end{tabular}

${ }^{1}$ Primeiro e último ciclos de pastejo. Os pastos ficaram abaixo da altura-meta de $70 \mathrm{~cm}$ de altura (Adaptado de Euclides et al., $2012 \mathrm{a}$ ).

${ }^{2}$ Considerando apenas os pastos que atingiram a meta de $90 \mathrm{~cm}$ de altura (Adaptado de Euclides et al., 2012a). 
apresentavam altura média, em torno de 65 e $55 \mathrm{~cm}$, respectivamente (Figuras 1 e 2). Note-se que o adiamento do início do pastejo até que a altura do dossel atingisse os 90 e $70 \mathrm{~cm}$ resultaria em menor produção animal durante a estação de crescimento da forrageira (Tabelas 3 e 4). Tal redução foi de $95 \mathrm{~kg} / \mathrm{ha}$ para os pastos de capim-mombaça manejados com resíduos de $30 \mathrm{~cm}$ e de $125 \mathrm{~kg} / \mathrm{ha}$ de peso corporal a menos para aqueles manejados a $50 \mathrm{~cm}$. Da mesma forma, considerando-se somente os pastos de capim-tanzânia que atingiram a meta

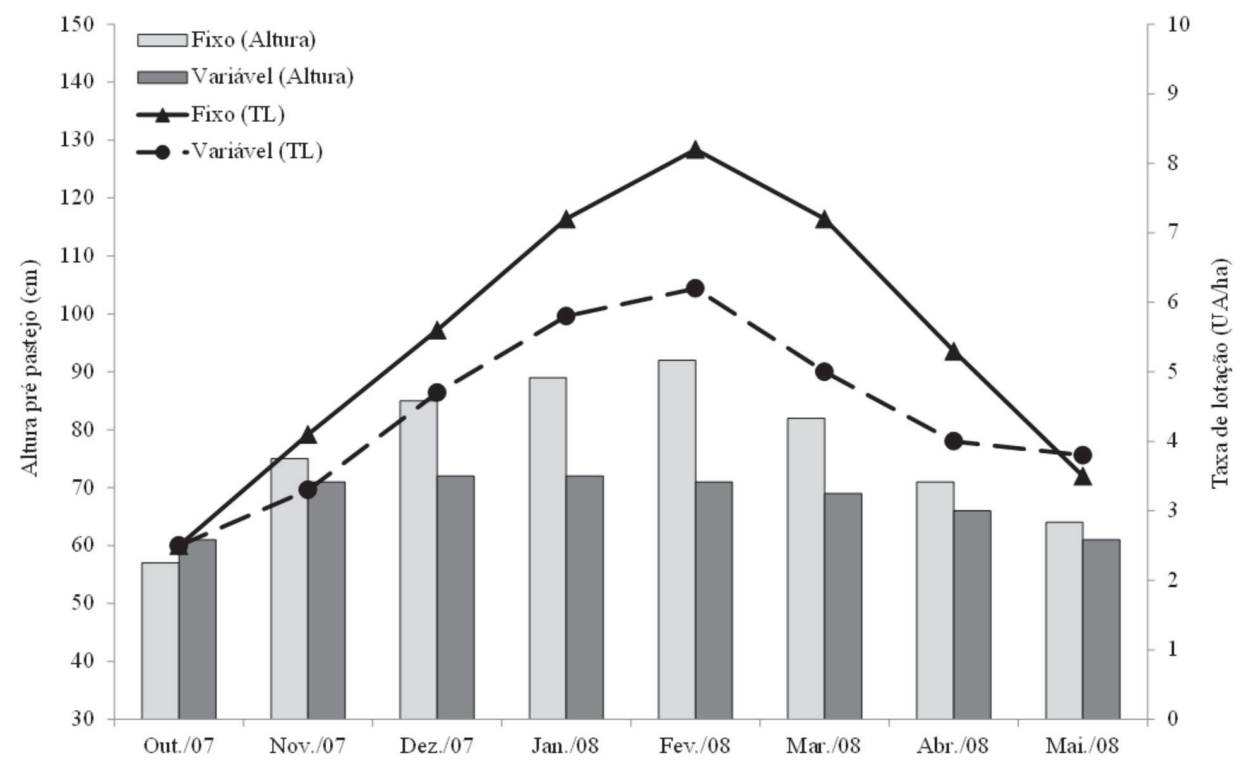

Figura 1. Médias das alturas dos pastos e da taxa de lotação, em pastos de capim-tanzânia em pastejo intermitente com intervalos de pastejos fixo e variável (Adaptado de Euclides et al. 2012a).

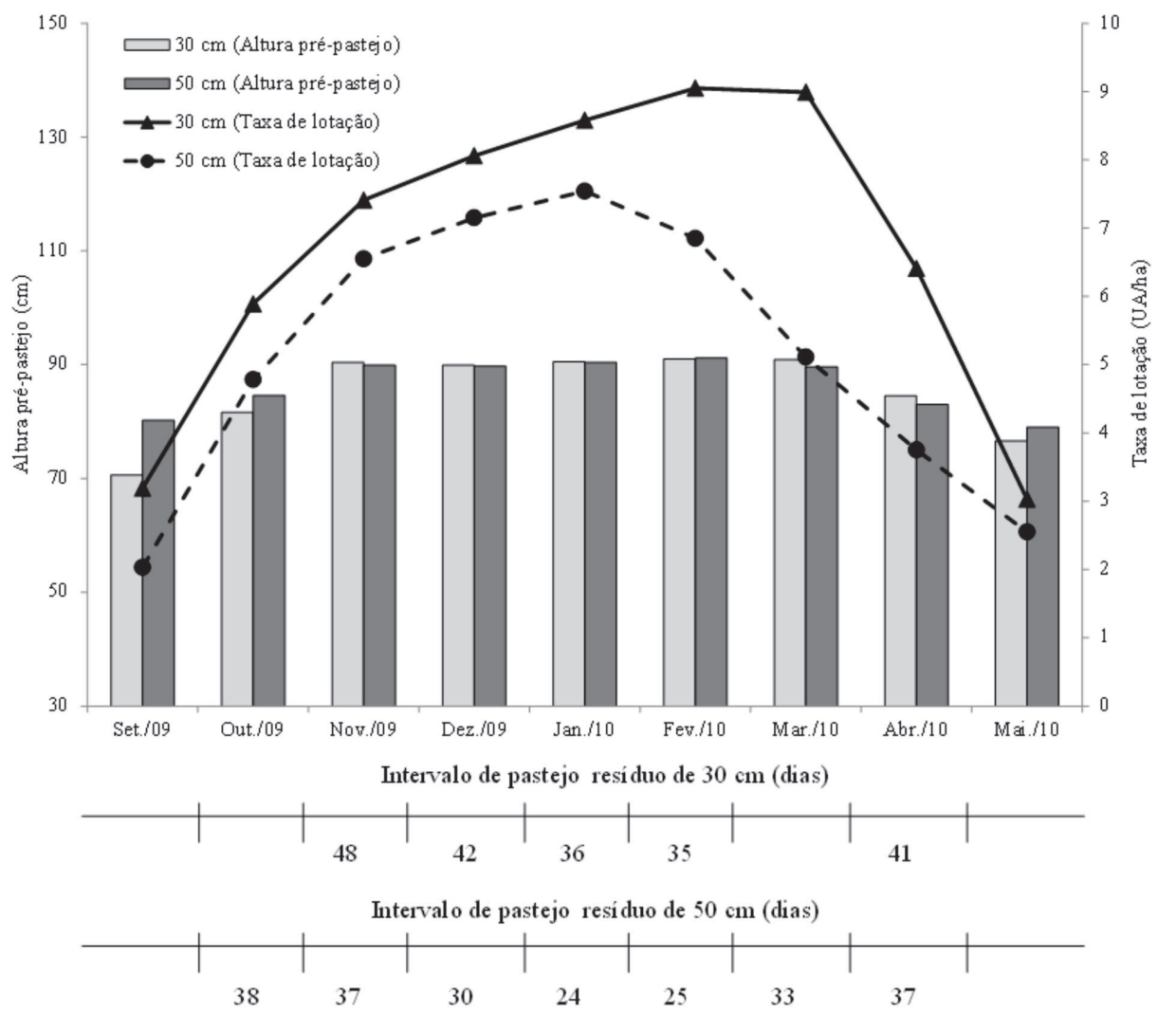

Figura 2. Alturas dos pastos no pré-pastejo, taxas de lotação e intervalos entre pastejos para pastos de capim-mombaça em pastejo intermitente com duas alturas de resíduos associadas a uma condição de pré-pastejo comum de $90 \mathrm{~cm}$ (Adaptado de Euclides et al., 2012b). 
de $70 \mathrm{~cm}$ de altura, o que ocorreu de 26 de outubro a 2 de abril (159 dias de uso), a diferença em ganho de peso por área entre as duas estratégias de manejo reduziu para $30 \mathrm{~kg} / \mathrm{ha}$ de peso vivo (Tabela 3 ).

Nesse contexto, Barbosa et al (2007) e Zanine et al. (2011) observaram que pastos de capim-tanzânia, manejados com 90 e $95 \%$ de IL, com as alturas de aproximadamente 60 e $70 \mathrm{~cm}$, não divergiram muito quanto à massa de forragem no pré-pastejo e apresentaram taxas de acúmulo de lâminas foliares semelhantes para as duas frequências de pastejo. Esses resultados permitem deduzir que, em situações de menor crescimento do pasto, a realização do pastejo mais frequente (90\% de IL) não compromete a produção de forragem do pasto e pode constituir alternativa para flexibilizar o manejo do pastejo. Ressalte-se que nos trabalhos conduzidos por Carnevalli et al., 2006; Barbosa et al., 2007, 2009, 2010; Pedreira et al., 2007; Da Silva et al., 2009; Giacomini et al., 2009; e Silveira et al., 2013 a deterioração do dossel ocorreu quando os pastos foram manejados além da condição de $95 \%$ IL. Portanto a altura, meta de manejo do pasto, correspondente a $95 \%$ de IL para interromper a rebrotação, deve ser vista como altura máxima na qual não há prejuízo na estrutura e na qualidade do pasto.

Essa análise comparativa permite refletir sobre o manejo em sistemas de produção reais, nos quais a redução de um a dois meses no uso do pasto durante o período das águas pode acarretar em prejuízos, pois o início da primavera e o fím do outono coincidem com o período em que há redução do crescimento e, de modo geral, o produtor tem dificuldade em remanejar os animais. Dessa forma, sugere-se que os pastos podem ser usados abaixo da altura-meta, desde que a taxa de lotação seja ajustada de acordo com sua taxa de crescimento (Figuras 1 e 2).

A necessidade de compreender aspectos da relação planta-animal e resposta dos animais às práticas de desfolha deve ser reconhecida (Da Silva e Carvalho, 2005; Carvalho et al, 2009). No entanto, esse tipo de pesquisa ainda precisa de uma quantidade considerável de esforços. Um resumo dos resultados para os cultivares dos gêneros Panicum e Brachiaria até aqui acumulados será apresentado.

Palhano et al. (2007) observaram que à medida que se aumentou a altura dos pastos de capim-mombaça de 60 para $140 \mathrm{~cm}$ houve acréscimo linear na massa do bocado; no entanto, houve aumento linear no tempo gasto por bocada, resultando em redução linear na taxa de bocados. Uma vez que o aumento no tempo por bocada foi proporcionalmente maior que o da massa de bocada, o consumo de forragem e a taxa de ingestão estabilizaram-se em $100 \mathrm{~cm}$ do dossel. Além disso, Palhano et al. (2006) observaram que os animais ajustam seus padrões de deslocamento à procura de forragem em resposta à estrutura do dossel forrageiro. Assim, com o aumento da altura do dossel, o número de estações alimentares diminuiu e o número de passos entre as estações alimentares aumentou, ampliando a exploração do ambiente de pastejo, demostrando, dessa forma, a importância do controle da estrutura do dossel como forma de criar ambientes pastoris adequados ao pastejo (Carvalho, 2005).

As modificações na estrutura da pastagem e o comportamento ingestivo de bovinos durante o rebaixamento dos pastos de capim-marandu foram estudados por Trindade (2007). Os tratamentos corresponderam a combinações entre duas intensidades de pastejo (resíduos pós-pastejo de 10 e $15 \mathrm{~cm}$ ) e dois intervalos entre pastejos (equivalente ao período de tempo necessário para que pastos atingissem $95 \%$ e $100 \%$ de IL). Durante o processo de pastejo, os tratamentos de $100 \%$ de IL resultaram em maiores bocados, mas menores taxas de ingestão e porcentagem de folhas na forragem consumidas em comparação com os $95 \%$ de IL pastagens. Os pastos manejados com 95/10 e 95/15 estiveram associados às maiores atividade de pastejo e taxa de ingestão de forragem, sugerindo maior ingestão diária de forragem. No entanto, no pasto 95/15 foi o que resultou na maior proporção de folhas na forragem ingerida e nos menores valores de frequência e intensidade de desfolhação de folhas. Esse padrão de desfolhação resultou em maior área foliar remanescente, favorecendo a rebrota seguinte e o rápido retorno dos pastos ao pastejo. A estratégia de pastejo que resultou em melhor utilização da forragem produzida foi aquela em que os pastejos foram realizados com $95 \%$ IL até uma altura de $15 \mathrm{~cm}$.

Difante et al. (2009) também observaram que à medida que os pastos de capim-tanzânia eram rebaixados houve decréscimos nas porcentagens de folhas na massa de forragem e acréscimos no tempo de pastejo pelos animais. A taxa de bocada, nos pastos com $25 \mathrm{~cm}$ de resíduo aumentou linearmente a uma taxa de 0,64 bocada/ minuto com o período de ocupação, o que representou 371 bocadas a mais para cada dia adicional de ocupação. No entanto, em pastos manejados com $50 \mathrm{~cm}$ de resíduo, a taxa de bocada não variou durante o período de ocupação, indicando que o manejo com resíduo póspastejo mais alto não interferiu severamente na estrutura do pasto, a fim de provocar variações na taxa de bocadas.

Euclides et al. (2012b) observaram decréscimo na ingestão de forragem de 2,6 para 2,0 kg de matéria seca por $100 \mathrm{~kg}$ de peso vivo pelos animais nos pastos manejados com o resíduo de $50 \mathrm{~cm}$ em relação aos pastos de $30 \mathrm{~cm}$. Além da dificuldade de preensão e de colheita da 
forragem pelos animais que tiveram que explorar o estrato de $30-50 \mathrm{~cm}$, estrato esse caracterizado por menores porcentagens de folhas, relação folha-colmo e valor nutritivo. O que concorda com as observações de Carvalho et al. (2009), a forma que o animal pasta durante o período de ocupação é função da estrutura do dossel definido no pré e pós-pastejo. Com base em diversos resultados de pesquisa, esses autores concluíram que com a redução da altura do pasto em mais do que $40 \%$ da altura inicial, a taxa de remoção de forragem decresce como consequência dos aumentos de colmo e material morto no horizonte de pastejo, limitando a profundidade de bocado.

\section{LOTAÇÃO CONTÍNUA}

O conhecimento das variáveis estruturais e da morfogênese das plantas forrageiras tem, também, se constituído em importante ferramenta para a determinação das condições de pasto adequadas para assegurar a produção animal em pastos de cultivares de $B$. brizantha em lotação contínua. Uma série de experimentos foi desenhada para avaliar as relações funcionais entre as respostas de plantas e animais para as estratégias de desfolhação caracterizadas por um rígido controle das alturas dos pastos (Tabela 5). Cultivares de Brachiaria brizantha foram utilizados com bovinos para manter alturas dos pastos entre 10 e $45 \mathrm{~cm}$. Nesses conjuntos de experimentos, independentemente do cultivar, local ou nível de adubação de manutenção, as taxas de acúmulo de forragem foram semelhantes para os pastos mantidos nas amplitudes de alturas estudadas, apesar do acréscimo na densidade populacional de perfilhos basais à medida que decresceu a altura do dossel (Tabela 5). Sbrissia e Da Silva (2008) explicaram esse fato pela compensação entre peso de perfilhos individuais e número de perfilhos; assim, pastos mantidos mais baixos possuíam alta densidade populacional de perfilhos pequenos e viceversa; demonstrando, assim, a grande flexibilidade de manejo desses cultivares.

Por outro lado, quando se analisa a estrutura do dossel que representa o ponto de origem das respostas das plantas como dos animais (Da Silva \& Nascimento Júnior, 2007), a massa de forragem continha baixas porcentagens de lâminas foliares, o que normalmente ocorre em pastagens em lotação contínua, consequentemente baixa relação folha-colmo, sendo maiores valores observados para pastos mantidos mais baixos. Também os pastos mantidos mais baixos apresentaram maiores densidade volumétrica e valor nutritivo da forragem quando comparados àqueles mantidos mais altos (Tabela 5). Apesar da estrutura do dossel mais favorável ao pastejo animal e do maior valor nutritivo dos pastos mantidos mais baixos, a ingestão de forragem foi menor para todos os cultivares (Tabela 5).

Segundo Da Silva et al (2013), os padrões de desfolhação dos perfilhos individuais revelaram que a cada evento de desfolhação cerca de $67 \%$ do comprimento do limbo foliar das folhas era removido, independentemente da altura do pasto e da frequência dos eventos de desfolhação ocorridos, indicando que os animais exploraram apenas o terço superior do dossel, ou seja, os primeiros 3,$3 ; 6,6 ; 9,9$; e $13,2 \mathrm{~cm}$ para os pastos mantidos a 10, 20, 30 e $40 \mathrm{~cm}$, o que explicou a grande variação na massa do bocado, que foi, respectivamente, de 0,$5 ; 0,8 ; 1,2$; e $1,5 \mathrm{~g} /$ bocado de matéria seca, resultando em consumo de forragem (CF) variando de 1,3 a 2,0 $\mathrm{kg}$ de MS por $100 \mathrm{~kg}$ de peso vivo e do ganho médio diário (GMD) de 0,190 a 0,930 (Tabela 5). Segundo Carvalho (1997), pasto mantido mais alto potencializa a profundidade do bocado, determinante da massa do bocado e, consequentemente, do consumo de forragem.

Carloto et al. (2011) observaram que apesar de menor ingestão de forragem pelos animais no pasto de capim-xaraés mantido a $15 \mathrm{~cm}$ (Tabela 5), o GMD foi semelhante aos daqueles nos pastos manejados nas demais alturas (Tabela 5). Uma vez que o consumo de nutrientes digestíveis é o produto da quantidade de forragem consumida pela digestibilidade dos nutrientes nessa forragem, provavelmente a maior digestibilidade in vitro da matéria orgânica (Tabela 5) compensou o menor CF pelos animais no pasto com $15 \mathrm{~cm}$. Por outro lado, o menor valor nutritivo do pasto com $45 \mathrm{~cm}$ (Tabela 5), provavelmente, limitou o GMD dos animais. No entanto, os autores ressaltaram que o pasto de capim-xaraés, manejado a $30 \mathrm{~cm}$, apresentou padrão de GMD relativamente mais estável do que aqueles observados nas demais alturas, ao longo do período das águas (Figura 3). Isso demonstra que essa altura de manejo apresenta menor influência das condições ambientais adversas e que a necessidade de ajuste na taxa de lotação foi menos frequente do que para os pastos mantidos a 15 e $45 \mathrm{~cm}$.

Esses resultados indicam o potencial para o desenvolvimento de estratégias de manejo do pastejo com base em metas da altura do pasto submetido à lotação contínua, como postulado por Hodgson e Da Silva (2002). Ressalta-se que em cada capim existe uma amplitude de condições de pasto específica para que as metas de produções por animal e por área possam ser alcançadas. No caso, para os três cultivares de $B$. brizantha apresentados na Tabela 6 a faixa ótima para o pastejo varia entre 15 e $30 \mathrm{~cm}$, dependendo se o objetivo do manejo for maior eficiência de pastejo ou maior desempenho por animal.

Em condições edafoclimáticas normais e mediante a inexistência de outra limitação de nutrientes, seguramente o nitrogênio é o fator de maior impacto na dinâ- 
mica de crescimento dos pastos de gramíneas, uma vez que ele acelera as taxas de crescimento e desenvolvimento da planta, aumenta o acúmulo de forragem e consequentemente influencia na estrutura do dossel (Duru e Ducroq, 2000). Nesse contexto, em uma série de trabalhos realizados de forma concomitante na mesma área experimental com capim-marandu submetido à lotação contínua, mantido a $30 \mathrm{~cm}$ de altura, avaliou-se o efeito das doses crescentes de nitrogênio $(0,150,300$ e $450 \mathrm{~kg} / \mathrm{ha}$ de N). Pereira et al. (2010) observaram acréscimos lineares nas taxas de aparecimento e de alongamento de folhas, no comprimento das folhas expandidas, na densidade populacional de perfilhos e no índice de área foliar à medida que se aumentou as doses de $\mathrm{N}$. Consequentemente, houve aumentos nas densidades volumétricas de folhas e de colmos nos pastos com maiores dose de N. No entanto, os aumentos nesses dois componentes morfológicos foram semelhantes, resultando na relação folha-colmo de 0,$72 ; 0,70 ; 0,68$; e 0,74 , respectivamente para pastos não adubadas e adubadas com 150, 300 e $450 \mathrm{~kg}$ ha-1 de N. Mesquita et al. (2010) observaram que o aumento das doses de $\mathrm{N}$ provocou aumentos de crescimento e de senescência da planta, os quais ocorreram de forma relativamemte proporcional, sugerindo um forte mecanismo de compensação. Guarda (2010) observou que, apesar do aumento em frequência de desfolhação causado pelas maiores densidades de lotação nos pastos com maiores doses de N, houve diminuição correspondente no tempo de vida da folha, resultando em pequena variação da eficiência de utilização da forragem produzida. A combinação dos resultados de Pereira et al. (2010), Mesquita et al. (2010) e Guarda (2010) revelou que apesar da grande amplitude das doses de nitrogênio utilizadas, houve um padrão comum de variação na estrutura dos dosseis, indicando que a altura do dossel correspondeu a uma forma eficiente de monitorar e controlar o processo de pastejo e a estrutura do dossel forrageiro.

\section{ESTACIONALIDADE DA PRODUÇÃO}

Independentemente das adubações, os capins tropicais não irrigados apresentam, de maneira geral, maiores taxas de acúmulo de forragem durante o verão, intermediárias no outono e na primavera e muito baixas no inverno. Sendo a exigência nutricional do rebanho constante, há desequilíbrio entre a produção de forragem e o requerimento de nutrientes pelo rebanho ao longo do

Tabela 5. Alturas do dossel, massa de forragem (MF; kg/ha), densidade populacional de perfilhos (DPP; número/m², taxa de acúmulo de forragem (TAF; kg/ha por dia), porcentagem de lâminas foliares (PLF), relação folha:colmo (RFC), densidade volumétrica (DV; kg/ ha por $\mathrm{cm}$ ), percentagens de proteína bruta $(\mathrm{PB})$ e de digestibilidade in vitro da matério orgânica (DIVMO), consumo voluntário de forragem (CF; $\mathrm{kg}$ de matéria seca de forragem por $100 \mathrm{~kg}$ de peso vivo) e ganho médio diário (GMD; $\mathrm{kg}$ ) para cultivares de $\mathrm{B}$. brizantha, sob lotação contínua

\begin{tabular}{|c|c|c|c|c|c|c|c|c|c|c|}
\hline Altura & MF & DPP & TAF & PLF & RFC & DIVMO & PB & DIV & $\mathbf{C F}$ & GMD \\
\hline \multicolumn{11}{|c|}{ B. brizantha cv. Marandu ${ }^{1}$ - Piracicaba } \\
\hline 10 & 5,5 & 1.069 & 72,0 & 21,9 & 0,77 & 506 & 13,7 & 67,1 & 1,31 & 0,190 \\
\hline 20 & 10,0 & 978 & 79,1 & 22,2 & 0,81 & 475 & 12,7 & 66,2 & 1,78 & 0,510 \\
\hline 30 & 13,8 & 865 & 73,8 & 20,3 & 0,73 & 424 & 12,4 & 63,1 & 1,84 & 0,750 \\
\hline 40 & 17,3 & 692 & 68,8 & 21,5 & 0,76 & 398 & 11,3 & 62,4 & 1,96 & 0,930 \\
\hline \multicolumn{11}{|c|}{ B. brizantha cv. Marandu ${ }^{2}$ - Campo Grande } \\
\hline 15 & 3,2 & 1.020 & 64,0 & 28,8 & 2,2 & 220 & 12,7 & 59,9 & 2,07 & 0,615 \\
\hline 30 & 6,1 & 853 & 59,3 & 20,9 & 1,2 & 212 & 11,0 & 58,0 & 3,04 & 0,628 \\
\hline 45 & 7,8 & 722 & 50,0 & 17,6 & 0,8 & 185 & 10,2 & 57,3 & 2,72 & 0,675 \\
\hline \multicolumn{11}{|c|}{ B. brizantha cv. Xaraés ${ }^{3}$ - Campo Grande } \\
\hline 15 & 2,6 & 644 & 59,9 & 32,6 & 1,9 & 175 & 11.5 & 61.7 & 1.88 & 0.724 \\
\hline 30 & 5,9 & 581 & 64,5 & 25,0 & 1,2 & 210 & 9.9 & 58.8 & 2.55 & 0.717 \\
\hline 45 & 7,7 & 485 & 72,1 & 20,9 & 0,9 & 170 & 9.4 & 56.8 & 2.34 & 0.580 \\
\hline \multicolumn{11}{|c|}{ B. brizantha cv. Piatã ${ }^{4}$ - Campo Grande } \\
\hline 15 & 1,9 & 568 & 63,8 & 29,5 & 1,5 & 118 & 12,3 & 65,1 & & 0,550 \\
\hline 30 & 3,3 & 603 & 73,6 & 27,6 & 1,1 & 109 & 11,0 & 62,6 & & 0,620 \\
\hline 45 & 4,2 & 518 & 69,7 & 31,2 & 1,2 & 94 & 11,1 & 62,2 & & 0,645 \\
\hline
\end{tabular}

${ }^{1}$ Período experimental de dezembro de 2001 a dezembro de 2002, adubação de manutenção (kg/ha): 300 de Ne 50 de $\mathrm{K}_{2} \mathrm{O}$ (Sbrissia \& Da Silva, 2008 ; Da Silva et al., 2013 ).

${ }^{2}$ Período experimental de dezembro de 2007 a dezembro de 2008, adubação de manutenção (kg/ha): 100 N e 200 da fórmula 0-20-20 (Paula et al., 2012). ${ }^{3}$ Período experimental de dezembro de 2007 a dezembro de 2008, adubação de manutenção (kg/ha): 100 N e 200 da fórmula 0-20-20 (Carloto et al., 2011). ${ }^{4}$ Período experimental de dezembro de 2008 a dezembro de 2009, adubação de manutenção (kg/ha): 90 N e 200 da fórmula 0-20-20 (Nantes, 2011). 


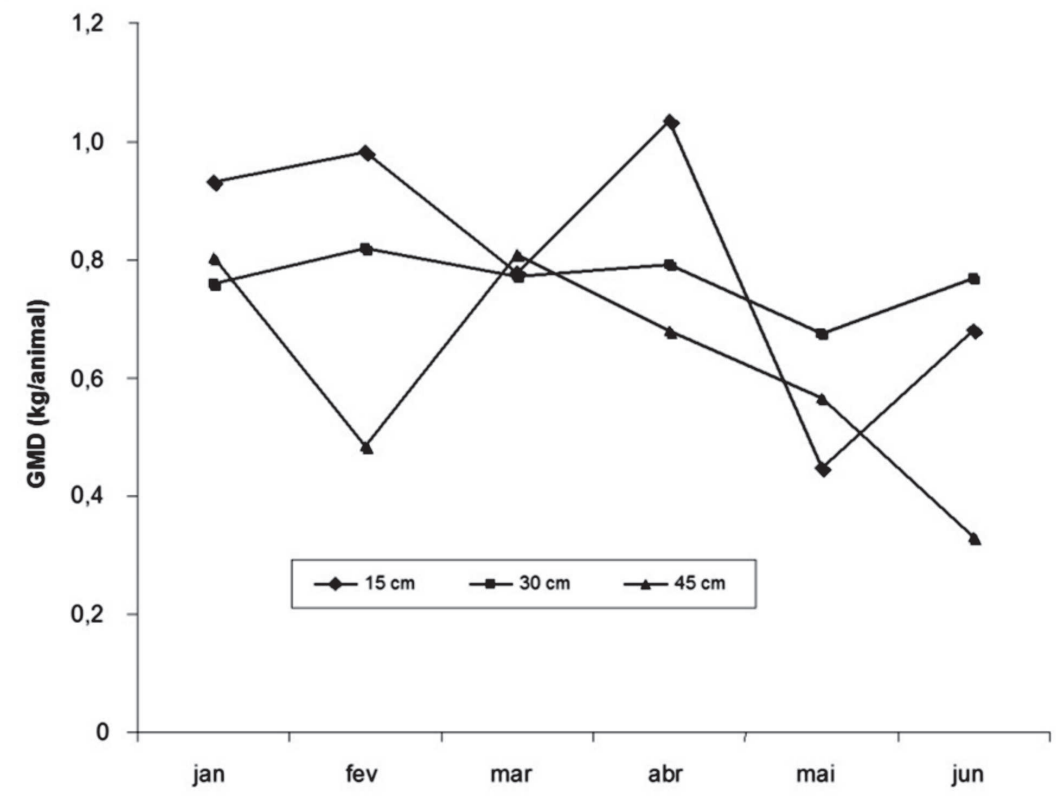

Figura 3. Ganho médio diário (GMD) dos animais em pastos de capim-xaraés manejados com 15,30 e $45 \mathrm{~cm}$ de altura, de acordo com meses do ano (Carloto et al., 2011).

Tabela 6. Desempenho animal e taxa de lotação em pastos de cultivares de Brachiaria brizantha sob lotação contínua, em função das alturas dos pastos

\begin{tabular}{lccccc}
\hline Capim & $\begin{array}{c}\text { Faixa de } \\
\text { pastejo }(\mathbf{c m})\end{array}$ & $\begin{array}{c}\text { Altura pasto } \\
(\mathbf{c m})\end{array}$ & $\begin{array}{c}\text { Taxa de } \\
\text { lotação }(\mathbf{U A} / \mathbf{h a})\end{array}$ & $\begin{array}{c}\text { Ganho de peso vivo } \\
\text { Por dia }(\mathbf{k g} / \mathbf{c a b})\end{array}$ & $\begin{array}{c}\text { Por área } \\
(\mathbf{k g} / \mathbf{h a})\end{array}$ \\
\hline Marandu $^{1}$ & 15 a 30 & 15 & 3,1 & 0,610 & 430 \\
& & 30 & 2,6 & 0,800 & 500 \\
Xaraés $^{1}$ & 15 a 30 & 15 & 3,7 & 0,560 & 560 \\
& & 30 & 3,1 & 0,670 & 600 \\
Piatã $^{2}$ & 15 a 30 & 15 & 3,3 & 0,590 & 540 \\
& & 30 & 2,7 & 0,720 & 570 \\
\hline
\end{tabular}

${ }^{1}$ Médias de três períodos das águas (Euclides et al., dados não publicados).

${ }^{2}$ Médias de dois períodos das águas (Euclides et al., dados não publicados).

ano. Assim, o manejo dos pastos e o manejo animal devem, dentro do possível, ser usados como instrumentos para equilibrar as variações estacionais dos pastos com as demandas nutricionais do animal. Por isso, o planejamento do uso das diferentes áreas de pasto em uma propriedade é de fundamental importância como forma de permitir a flexibilidade do manejo dos animais, mantendo o sistema sustentável. Dessa forma, a estruturação de sistemas de produção sustentáveis de bovinos em pastos resume-se basicamente no manejo correto dos pastos durante o período das águas (outubro a abril) e no uso da suplementação alimentar durante o período seco (maio a setembro).

Independentemente do nível de insumo ou do critério utilizado como meta de pastejo, a manipulação da taxa de lotação nas áreas pastejadas (Figuras 1 e 2; Tabelas 5 e 6) é que dará a flexibilidade de controle do pasto e do processo de pastejo, uma vez que mesmo no período das águas a taxa de crescimento não é unifor- me, o que pode ser constatado nas Figuras 1 e 2 pelos diferentes intervalos de pastejo para se atingir uma mesma condição de pasto no pré-pastejo. Consequentemente, há variações nas taxas de lotação ao longo do período das águas, para possibilitar os ajustes das alturas-meta.

A maior dificuldade na assimilação desse critério de manejo pelos produtores é consequência da decisão de o que fazer com os animais que são retirados do pasto, no caso de menor crescimento da planta. A principal resposta a esta pergunta resume-se no planejamento e acompanhamento da produção de pasto de todas as áreas da propriedade. Nesse sentido, é importante notar que para se proceder ao manejo correto dos pastos baseado nesses novos conceitos são necessárias áreas de reservas para realocação dos animais sempre que não for possível atingir a altura-meta (lotação rotacionada) ou manter a altura-meta (lotação contínua). Na prática, durante o período das águas, o uso de áreas de reserva tem sido 
necessário no início da primavera e no fim do outono e, eventualmente, na ocorrência de veranicos. Exemplos detalhados de cálculo de áreas de pastos-reserva, dentro de um sistema de produção, podem ser encontrados em Euclides (2009). O manejo do pastos-reserva também é de grande importância, uma vez que a meta do sistema de produção é bom desempenho animal, independentemente do pasto em que ele está.

No entanto, se a opção for pela não utilização de pastos-reserva, a alternativa seria manter a TL fixa e ajustar a área a ser manejada pelo uso de cerca elétrica, o que permitiria equilibrar a oferta e a demanda de forragem durante o período das águas. Nesse caso, o excedente de forragem produzida seria conservado, reduzindo-se a necessidade de áreas exclusivas para a conservação de forragem a ser utilizada sempre que necessário. Todavia, há de se considerar os aspectos relacionados com a eficiência dos sistemas de colheita, de processamento, de conservação e os aspectos econômicos.

Durante o período seco ocorre marcante redução na produção de forragem e, consequentemente, na produção animal. A intensificação da produção, eliminando ou diminuindo seu efeito, tem sido um desafio. A suplementação, tanto de volumosos quanto de concentrados, tem sido utilizada com sucesso para resolver esse problema (Euclides e Medeiros, 2005; Euclides e Montagner, 2013; Euclides et al., 2014). Então, para se intensificar a produção das pastagens no período das águas, o produtor tem que estar preparado para a produção de alimentos suplementares para serem utilizados durante o período seco.

A diversificação das pastagens pode ser uma maneira simples de solucionar esse problema. Assim, recomenda-se que os pastos mais produtivos tenham seu uso concentrado no período das águas, sendo manejados como descrito anteriormente, para permitir o melhor aproveitamento da forragem de alta qualidade produzida. Complementarmente, forrageiras de potencial produtivo menor poderiam ser pastejadas durante as águas, permitindo assim o ajuste do manejo das áreas mais produtivas. Aquelas apropriadas para o diferimento poderiam ser vedadas no fim do verão para serem pastejadas durante a seca.

\section{CONCLUSÕES}

Com base nos resultados publicados, recomendações de manejo de pastejo para alguns cultivares podem ser elaboradas.

Existe grande potencial para o desenvolvimento de estratégias de manejo do pastejo tanto para a lotação contínua quanto para a rotacionada, com base em metas de altura do pasto.
No caso de lotação rotacionada, o intervalo entre pastejo deve ser definido com base na altura do dossel correspondente a $95 \%$ de interceptação de luz, garantindo, dessa forma, a produção de forragem de alta qualidade. A escolha do resíduo pós-pastejo pode ser mais flexível e deve estar em consonância com a eficiência de colheita da forragem e o nível de desempenho animal almejados no sistema de produção. Em pastos não adubados ou em solos de baixa fertilidade natural, menor intensidade de pastejo pode ser mais adequada para garantir a sustentabilidade da pastagem.

Já para os pastos submetidos à lotação contínua, existe uma faixa ótima de altura do pasto que pode ser utilizada, dependendo se o objetivo do manejo for maior o desempenho por animal ou maior produção animal por área.

\section{REFERÊNCIAS}

Barbosa RA, Nascimento Jr D, Euclides VPB, Da Silva SC, Zimmer AH \& Torres Jr RAA (2007) Capim-tanzânia submetido a combinações entre intensidade e frequência de pastejo. Pesquisa Agropecuária Brasileira, 42:329-340.

Barbosa RA, Rosa PR \& Lima GO (2010) Capim-massai manejado em diferentes combinações de intensidade e frequência de corte. Disponível em: <www.sbz.org.br〉. Acessado em: 25 de agosto de 2014.

Barbosa RA, Rosa PR, Santos VAC, Bastos JA \& Trindade DES (2009) Acúmulo de forragem do capim-milênio sob regimes de corte. Disponível em: <www.sbz.org.br>. Acessado em: 25de agosto de 2014.

Carloto MN, Euclides VPB, Montagner DB, Lempp B, Difante GS \& Paula CCL (2011) Desempenho animal e características de pasto de capim-xaraés sob diferentes intensidades de pastejo, durante o período das águas. Pesquisa Agropecuária Brasileira, 46:97-104.

Carnevalli RA, Da Silva SC, Bueno AAO, Uebele MC, Hodgson J, Silva GN \& Morais JPG (2006) Herbage production and grazing losses in Panicum maximum cv. Mombaça under four grazing managements. Tropical Grasslands, 40:165-176.

Carvalho PCF (1997) A estrutura da pastagem e o comportamento ingestivo de ruminantes em pastejo. In: Simpósio sobre Avaliação de Pastagens com Animais, Maringá. Anais, Universidade Estadual de Maringá. p.25-52.

Carvalho PCF (2005) O manejo da pastagem como gerador de ambientes pastoris adequados à produção animal. In: $22^{\circ}$ Simpósio sobre Manejo da Pastagem, Piracicaba. Anais, FEALQ. p.07-31.

Carvalho PCF, Trindade JK, Da Silva SC, Bremm C, Mezzalira JC, Nabinger C, Amaral MF, Carassai IJ, Martins RS, Genro TCM, Gonçalves EM, Amaral GA, Gonda HL, Poli CHEC \& Santos DT (2009) Consumo de forragem por animais em pastejo: analogias e simulações em pastoreio rotativo. In: $25^{\circ}$ Simpósio Internacional de manejo de pastagens, Piracicaba. Anais, FEALQ. p.61-93.

Carvalho PCF, Canto MW \& Moraes A (2004) Fontes de perdas de forragem sob pastejo: forragem se perde? In: $2^{\circ}$ Simpósio sobre Manejo Estratégico da Pastagem, Viçosa. Anais, Suprema Gráfica e Editora Ltda. p.387-418.

Cunha BAL, Nascimento Junior D, Silveira MCT, Montagner DB, Euclides VPB, Da Silva SC, Sbrissia AF, Rodrigues CS, Sousa BML, Pena KS, Vilela HH \& Silva WL (2010) Effects of two post-grazing heights on morphogenic and structural characteristics of guinea grass under rotational grazing. Tropical Grassland, 44:253-259. 
Da Silva SC, Gimenes FMA, Sarmento DOL, Sbrissia AF, Oliveira DE, Hernadez-Garay A \& Pires AV (2013) Grazing behaviour, herbage intake and animal performance of beef cattle heifers on marandu palisade grass subjected to intensities of continuos stocking management. Journal of Agricutural Science, 151:727-739.

Da Silva SC \& Carvalho PCF (2005) Foraging behaviour and herbage intake in the favourable tropics/subtropics. In: McGilloway DA (Ed.) Grassland: a global resource. Wageningen, Wageningen Academic Publishers. p.81-95.

Da Silva SC \& Nascimento Jr. D (2007) Avanços na pesquisa com plantas forrageiras tropicais em pastagens: características morfofisiológicas e manejo do pastejo. Revista Brasileira de Zootecnia, 36:121-138.

Da Silva SC, Bueno AAO, Carnevalli RA, Ubele MC, Bueno FO, Hodgson J \& Morais JPG (2009) Sward structural characteristics and herbage accumulation of Panicum maximum cv. Mombaça subjected to rotational stocking managements. Scientia Agricola, 66:8-19.

Dias-Filho MB (2011) Degradação de pastagens: processos, causas e estratégias de recuperação. $4^{\mathrm{a}}$ ed. Belém, Embrapa Amazônia Oriental. $215 \mathrm{p}$.

Difante GS, Euclides VPB, Nascimento Jr. D, Da Silva SC, Torres Jr. RAA $\&$ Sarmento DOL (2009) Ingestive behaviour, herbage intake and grazing efficiency of beef cattle steers on tanzânia guineagrass subjected to rotational stocking managements. Revista Brasileira de Zootecnia, 38:1001-1008.

Difante GS, Euclides VPB, Nascimento Jr. D, Da Silva SC, Barbosa RA \& Torres Jr. AAR (2010) Desempenho e conversão alimentar de novilhos de corte em capim-tanzânia submetido a duas intensidades de pastejo sob lotação rotativa. Revista Brasileira de Zootecnia, 39:3341.

Duru M \& Ducrocq H (2000) Growth and senescence of the successive leaves on a Cocksfoot tiller. Effect of nitrogen and cutting regime. Annals of Botany, 85:645-653.

Euclides VBP \& Montagner DB (2013) Estratégias para intensificação do sistema de produção. In: Rosa NA, Martins EM, Menezes GRO \& Silva LOC (Eds.) Melhoramento genético aplicado em gado de corte: Programa Geneplus-Embrapa. Brasília, Embrapa. p.49-60.

Euclides VPB (2009) Planejamento do uso de áreas de pastagens em sistema de produção animal em pasto. In: $25^{\circ}$ Simpósio sobre Manejo da Pastagem, Piracicaba. Anais, FEALQ. p.117-149.

Euclides VPB, Difante GS, Montagner DB, Barbosa RA \& Costa JAR (2012a) Desempenho animal em pastos de capim-tanzânia submetidos a duas estratégias de desfolhação. Disponível em: <www.sbz.org.br>. Acessado em: 13 de agosto de 2014

Euclides VPB, Euclides Filho K, Montagner DB, Figueiredo GR \& Lopes FC (2014) Alternatives for intensification of beef production under grazing. Tropical Grasslands - Forrajes Tropicales, 2:48-50.

Euclides VPB, Lopes FC, Nascimento Jr. D, Da Silva SC, Difante GS \& Barbosa RA (2012b) Desempenho animal em pastos de capimmombaça sob duas intensidades de pastejo. Disponível em: <www.sbz.org.br>. Acessado em: 12 de agosto de 2014.

Euclides VPB \& Medeiros SR (2005) Suplementação animal em pastagens e seu impacto na utilização da pastagem. In: $22^{\circ}$ Simpósio sobre Manejo da Pastagem, Piracicaba. Anais, FEALQ. p.33-70.

Giacomini AA, Da Silva SC, Sarmento DOL, Zeferino CV, Souza Jr. SJ, Trindade JK, Guarda VA \& Nascimento Jr. D (2009) Growth of marandu palisadegrass subjected to strategies of intermitente stocking. Scientia Agricola, 66:733-741.

Gimenes FMA, Da Silva SC, Fialho CA, Gomes MB, Berndt A, Gerdes L \& Colozza MT (2011) Ganho de peso e produtividade animal em capim-marandu sob pastejo rotativo e adubação nitrogenada. Pesquisa Agropecuária Brasileira, 46:751-759.
Guarda VDA (2010) Frequencia e severidade de desfolhação e eficiência de utilização de forragem em pastos de capim-marandu manejados sob lotação contínua e ritmos de crescimento induzidos por fertilização nitrogenada. Tese de Doutorado. Escola Superior de Agricultura “Luiz de Queiroz”, Piracicaba. 118p.

Hodgson J \& Da Silva SC (2002) Options in tropical pasture management In: $39^{a}$ Reunião Anual da Sociedade Brasileira de Zootecnia, Recife. Anais, SBZ. p.180-202.

Mesquita P, Da Silva SC, Paiva AJ, Caminha FO, Pereira LET, Guarda VD \& Nascimento Jr D (2010) Structural characteristics of marandu palisadegrass swards subjected to continuous stocking and contrasting rhythms of growth. Scientia Agricola, 67:23-30.

Nantes NN (2011) Produção animal, morfogênese e acúmulo de forragem do capim-piatã submetido à intensidades de pastejo sob lotação contínua. Dissertação de Mestrado. Universidade Federal de Mato Grosso do Sul, Campo Grande. 58p.

Nascimento Jr. D, Barbosa RB, Marcelino KRA, Garcez Neto AF, Difante GS \& Lopes, BA (2003) A produção animal em pastagens no Brasil: uso do conhecimento técnico e resultados. In: Peixoto AM, Moura JC, Da Silva SC \& De Faria VP (Eds.) $20^{\circ}$ Simpósio sobre Manejo da Pastagem, Piracicaba. Anais, FEALQ. p.1-82.

Palhano AL, Carvalho PCF, Dittrich JR, Moraes A, Da Silva SC \& Monteiro ALG (2006) Padrões de deslocamento e procura de forragem de novilhas leiteiras em pastagem de capim-mombaça. Revista Brasileira de Zootecnia, 35:2253-2259.

Palhano AL, Carvalho PCF, Dittrich JR, Moraes A, Da Silva SC \& Monteiro ALG (2007) Características do processo de ingestãode forragem por novilhas holandesas em pastagem de capim-mombaça. Revista Brasileira de Zootecnia, 36:1014-1021.

Paula CCL, Euclides VPB, Montagner DB, Lempp B, Difante GS \& Carloto MN (2012) Estrutura do dossel, consumo e desempenho animal em pastos de capim-marandu sob lotação continua. Arquivos Brasileiros de Medicina Veterinária e Zootecnia, 64:169-176.

Pedreira BC, Pedreira CGS \& Da Silva SC (2007) Estrutura do dossel e acúmulo de forragem de Brachiaria brizantha cultivar xaraés em resposta a estratégias de pastejo de desfolhação. Pesquisa Agropecuária Brasileira, 42:281-287.

Pedreira BC, Pedreira CGS \& Da Silva SC (2009) Acúmulo de forragem durante a rebrotação de capim-xaraés submetido a três estratégias de desfolhação. Revista Brasileira de Zootecnia, 38:618-625.

Pereira LET, Paiva AJ, Da Silva SC, Caminha FO, Guarda VA \& Pereira PM (2010) Sward structure of marandu palisadegrass subjected to continuous stocking and nitrogen-induced rhythms of growth. Scientia Agricola, 67:531-539.

Sbrissia AF \& Da Silva SC (2008) Compensação tamanho/densidade populacional de perfilhos em pastos de capim-marandu. Revista Brasileira de Zootecnia, 37:35-47.

Silveira MCT, Da Silva SC, Sousa Jr. SJ, Barbero LM, Rodrigues CS, Limão VA, Pena KS \& Nascimento Jr. D (2013) Herbage acumulation and grazing losses on Mulato grass subjected to strategies of rotational stocking management. Scientia Agricola, 70:242-249.

Trindade JK (2007) Modificações na estrutura do pasto e no comportamento ingestivo de bovinos durante o rebaixamento do capimmarandu submetido a estratégias de pastejo rotacionado. Dissertação de Mestrado. Escola Superior de Agricultura "Luiz de Queiroz", Piracicaba. 162p.

Zanine AM, Nascimento Jr. D, Santos MER, Pena KS, Da Silva SC \& Sbrissia AF (2011) Características estruturais e acúmulo de forragem em capim-tanzânia sob pastejo rotativo Revista Brasileira de Zootecnia, 40:2364-2373.

Zanini GD, Santos GT \& Sbrissia AF (2012) Frequencies and intensities of defoliation in Aruana Guineagrass swards: accumulation and morphological composition of forage. Revista Brasileira de Zootecnia, 41:905-913. 